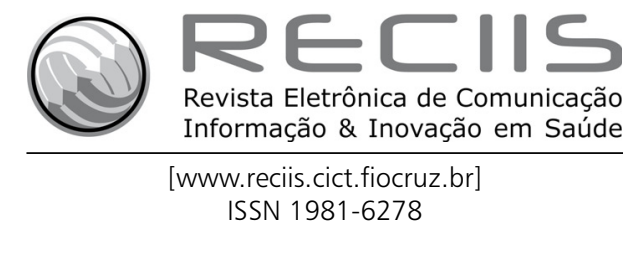

SUPLEMENTO - BIOINFORMÁTICA E SAÚDE

Apresentação

\title{
Bioinformática e saúde: uma visão geral
}

DOI: 10.3395/reciis.v1i2.Sup.97pt

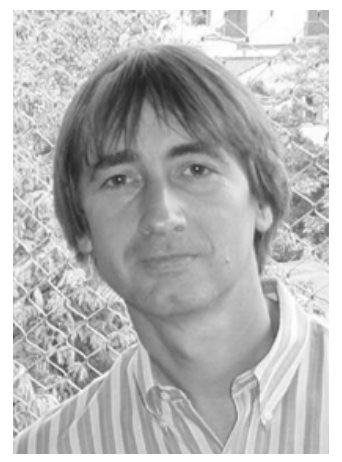

\author{
Wim Degrave \\ Editor Convidado \\ Instituto Oswaldo Cruz da \\ Fundação Oswaldo Cruz, \\ Rio de Janeiro, Brasil \\ wdegrave@fiocruz.br
}

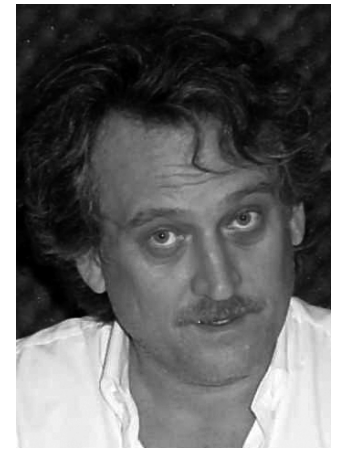

Conjuntos de dados sempre crescentes, novas fronteiras na ciência, o desenvolvimento de novas abordagens para análise e apresentação de dados, e a investigação de novas e complexas perguntas são as forças motrizes da bioinformática. Por sua vez, a disponibilidade de ferramentas de hardware mais velozes e potentes e o desenvolvimento contínuo das ciências da computação são suas principais forças de sustentação.

No início dos anos 1980, a bioinformática não era uma nova disciplina muito popular. Vista como indulgência com um novo brinquedo pelos biólogos e como um campo muito distante e estranho de aplicação pelos cientistas da computação, a disciplina encontrou poucos adeptos. Entretanto, a busca por sítios de restrição, a análise de composição de seqüências ou uma análise FASTA contra um banco de dados, mesmo que ainda reduzido, logo foram transformadas em ferramentas muito úteis. A disponibilização de pacotes acadêmicos de programas de análise de seqüências como Staden, o GCG (Genetics Computer Group da Universidade de Wisconsin) e alguns pacotes comerciais estimularam consideravelmente a bioinformática. Em outras áreas com disponibilidade de software de domínio público, como a filogenética, a análise computacional rapidamente se tornou essencial. Entretanto, é provável que somente após a dramática multiplicação, em tamanho e em número, dos bancos de dados de seqüências resultantes dos projetos genoma, que a bioinformática tenha sido amplamente reconhecida como uma disciplina chave para a nova era da genética, da biotecnologia e da biologia de sistemas. Modelagem molecular, bioestatística e outros campos passaram por um grande desenvolvimento, ao mesmo tempo em que havia um crescente interesse dos cientistas das áreas de computação pela aplicação de metodologias, algoritmos, estruturação e mineração de bancos de dados no campo exótico da biologia, induzindo a tão necessária multidisciplinaridade.

A bioinformática também foi considerada como um campo onde pesquisadores nos países em desenvolvimento pudessem competir em igualdade de condições com pesquisadores na Europa ou nos Estados Unidos. Apesar desse enunciado não ser completamente verdadeiro, é preciso reconhecer que a bioinformática é muito menos sensível do que outros campos às barreiras econômicas e burocráticas que atrasam a pesquisa básica e a aplicada nos países em desenvolvimento.

Este Suplemento da RECIIS é dedicado a diferentes aspectos da bioinformática. Não é possível oferecer uma completa revisão do campo em pouco espaço, mas foram abordados diversos aspectos relevantes para grupos de pesquisa nesta área. O suplemento ilustra tópicos como a organização de uma plataforma tecnológica de bioinformática para suporte institucional, discussões sobre diversos aspectos de genômica funcional (por exemplo, em dengue e leptospirose), o desenvolvimento de novas metodologias e ferramentas para análise, e o uso de regras gramaticais e lingüísticas para a análise de regiões biológicas regulatórias. 


\section{Sobre os autores}

\section{Wim Degrave}

Graduado em Química, com doutorado em Biologia Molecular na Universidade Federal de Ghent, na Bélgica, em 1985. Desde 1985 é Pesquisador Titular na Fiocruz. Além disso, foi pesquisador visitante no Instituto Pasteur, Paris no período de 1999-2000. Atualmente é chefe do Laboratório de Genômica Funcional e Bioinformática do Instituto Oswaldo Cruz, e coordenador para programas de fomento e infra-estrutura da Vice-Presidência de Pesquisa e Desenvolvimento Tecnológico da Fiocruz desde 2002. Suas principais áreas de atuação são genômica funcional, bioinformática e biotecnologia.

\section{Carlos José Saldanha Machado}

Doutor em Antropologia Social pela Université Paris V - Sciences Humaines Sorbonne, mestre em Ciências da Engenharia de Produção (área de Política de Ciência e Tecnologia) pela Coordenação dos Programas de Pós-Graduação em Engenharia da Universidade Federal do Rio de Janeiro. Atualmente, (1) na Fundação Oswaldo Cruz, é Pesquisador em Ciência e Tecnologia e Chefe do Laboratório de Ciência, Tecnologia e Inovação em Saúde do Instituto de Comunicação e Informação Científica e Tecnológica em Saúde; (2) na Universidade do Estado do Rio de Janeiro, é professor do Programa de Pós-Graduação em Meio Ambiente (Doutorado) responsável pela disciplina "Política Ambiental Brasileira"; (3) no Ministério da Educação, é Avaliador Institucional e de Cursos do Sistema Nacional de Avaliação da Educação Superior. Atua na área de sociologia e antropologia, com ênfase: nos estudos sociais da ciência, da tecnologia e da inovação em saúde; na gestão da pesquisa em saúde; nas políticas públicas de meio ambiente e saúde. Publicou, ao longo dos últimos 5 anos 4 livros e inúmeros artigos no Brasil. Seus novos projetos incluem pesquisas sobre: o novo regime de produção e de regulação do conhecimento científico e tecnológico em biomedicina; as mudanças recentes na configuração da biociência, especialmente nas infra-estruturas de produção do conhecimento; a transposição local de modelos internacionais de organização da pesquisa em biomedicina; a política de ciência, tecnologia e inovação em saúde da Fundação Oswaldo Cruz. 